\title{
In search of the elusive $\operatorname{IrB}_{2}$ : Can mechanochemistry help?
}

Zhilin Xie $^{\mathrm{a}}$, Richard G. Blair ${ }^{\mathrm{a}, \mathrm{b}}$, Nina Orlovskaya ${ }^{\mathrm{a} *}$, David A. Cullen ${ }^{\mathrm{c}}$, Saul H. Lapidus ${ }^{\mathrm{d}}$, Dariusz Kata $^{\mathrm{e}}$, Paweł Rutkowski ${ }^{\mathrm{e}}$ and Jerzy Lis ${ }^{\mathrm{e}}$

${ }^{a}$ Department of Mechanical and Aerospace Engineering, University of Central Florida, Orlando, FL 32816, USA

${ }^{\mathrm{b}}$ Department of Physics, University of Central Florida, Orlando, FL 32816, USA

${ }^{c}$ Materials Science \& Technology Division, Oak Ridge National Laboratory, Oak Ridge, TN 37831, USA

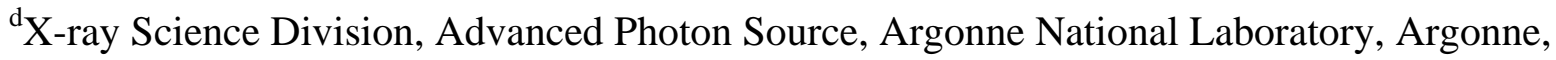
Illinois, 60439, USA

${ }^{\mathrm{e}}$ AGH University of Science and Technology in Krakow, Faculty of Materials Science and Ceramics, Department of Ceramics and Refractories, al. Mickiewicza 30, 30-059 Krakow

* Corresponding author: Nina Orlovskaya

E-mail: Nina.Orlovskaya@ucf.edu

Address: University of Central Florida, 4000 Central Florida Blvd, Orlando, FL 32816, USA

Telephone: 407-913-4438. Fax: 407-823-0208.

Keywords: Iridium diboride; Mechanochemistry; Ceramics

Abstract:

The previously unknown hexagonal $\operatorname{ReB}_{2}$-type $\operatorname{IrB}_{2}$ diboride and orthorhombic $\operatorname{IrB}$ monoboride phases were produced by mechanochemical syntheses. High energy ball milling of elemental Ir and B powder for 30 hours, followed by annealing of the powder at $1050{ }^{\circ} \mathrm{C}$ for 48 hours, resulted in the formation of the desired phases. Both traditional laboratory and high resolution synchrotron X-ray diffraction (XRD) analyses were used for phase identification of the synthesized powder. In addition to XRD, scanning electron microscopy and transmission 
electron microscopy were employed to further characterize the microstructure of the phases produced.

\section{Introduction}

Borides are utilized in a range of industrial applications due to their unique electrical, thermal, mechanical and catalytic properties where metal diborides are of particular interest. Titanium diboride $\left(\mathrm{TiB}_{2}\right)$ ceramics have a very high Young's modulus ( 565 GPa) [1], zirconium and hafnium diboride $\left(\mathrm{ZrB}_{2}\right.$ and $\mathrm{HfB}_{2}$, respectively) composites exhibit high oxidation resistance [2-6], magnesium diboride $\left(\mathrm{MgB}_{2}\right)$ is a superconducting phase with a $T_{c}$ among the highest of the conventional superconductors [7] and niobium diboride $\left(\mathrm{NbB}_{2}\right)$ nanoparticles have applications in catalysis as well as reversible hydrogen storage [8]. While many of the diborides find practical uses as abrasion and oxidation resistant coatings, there are ongoing searches for new phases and compositions that will possess interesting and useful properties. In recent years, $\mathrm{Re}, \mathrm{Os}, \mathrm{Rh}, \mathrm{Cr}$, and $\mathrm{W}$ borides have been studied as for their ultra-hardness and superior stiffness [9-15]. Interestingly, no experimental evidence currently exists for $\operatorname{IrB}_{2}$ even though the other elements in the group readily form diborides. Although first principles calculations have predicted that $\mathrm{IrB}_{2}$, which is expected to adopt an orthorhombic $\mathrm{OsB}_{2}$-type structure, would be thermodynamically stable, no $\operatorname{IrB}_{2}$ phases have been synthesized experimentally [16]. However, a number of compounds have been prepared in the Ir-B system with lower than a 1:2 metal: boron stoichiometry. Phases such as $\operatorname{IrB}_{1.35}$ and $\mathrm{IrB}_{1.1}$ as well as the metal-rich phases $\operatorname{IrB}_{0.9}$ and $\mathrm{IrB}_{0.7}$ have been reported in a number of publications [17-24] and some of their properties have been investigated [12, 25-27]. Very high Vickers hardness of $49.8 \mathrm{GPa}$ at $0.49 \mathrm{~N}$ load was reported for $\operatorname{IrB}_{1.35}[12]$. It has been predicted $[28,29]$ that the mechanical properties of borides could be improved by increasing the concentration of boron atoms in the sublattice of the 
transition metals, as an increase in boron atom content in a boride's unit cell would increase the amount of the covalent bonding in the lattice, which would improve the strength, hardness and stiffness of the ceramic. Therefore, increasing the boron content in the iridium sublattice should produce a material with superior mechanical properties and high chemical stability.

Recently, mechanochemical syntheses have been employed in the preparation of such difficult to process boron-rich solids as $\mathrm{ReB}_{2}$ and $\mathrm{OsB}_{2}$ ceramics. [30-33] Mechanochemical synthesis usually involves the high energy milling of powder using special mills where the milling occurs by high axial and shear forces produced by frequent impact events when balls hit the walls of the milling vial. A movie illustrating the ball movement and applied impact axial and shear stresses during high-energy ball milling can be found in the online supporting information. Photographs of a SPEX 8000 high energy ball mill along with a vial lined with WC and WC balls used for the mechanochemical synthesis of compounds are shown in Fig. 1 A and B. The frequencies of axial and shear impact stresses generated by the movement of the WC balls inside the empty WC vial during SPEX8000 ball mill operation are shown in Fig. $1 \mathrm{C}$ and $\mathrm{D}$, respectively, where both axial and shear applied stresses contribute to the fracture of particles followed by solid state diffusion reactions leading to the formation of new compounds. In the above simulation, Hertzian model [34] was used to determine the forces, velocities, and deformations produced during impact events. [35] This model utilizes the elastic properties of the materials of vial and balls involved in these collisions. The discrete element model software package EDEM, published by DEM solutions, was used to implement these calculations. [36] A schematic presentation of the axial and shear stresses acting on the particle during milling is shown in Fig. 2A. Shear stress and strain play a major role in the mechanochemical synthesis as shear strength of many compounds is much lower in comparison with compressive uniaxial 
strength. Thus, if shear deformations are present, the solid-state synthesis could be favored over approaches where only axial or hydrostatic pressure is acting alone. The estimated applied axial and shear stresses present during mechanochemical synthesis as a function of contact area are shown in Fig. 2B. These applied stresses will result in atomic level shear stresses acting on the particles through plastic deformation, which is very important in facilitation of solid-state chemical reactions by mechanochemistry.

Mechanochemical syntheses involving rhenium and osmium metal powders with elemental boron powders by high energy ball milling for an extended periods of time using WC media and balls allowed production of the difficult to synthesize hexagonal $\mathrm{ReB}_{2}$ and $\mathrm{OsB}_{2}$ phases. In fact, this approach is the only currently known route to hexagonal $\mathrm{OsB}_{2}-$ a metastable high-pressure phase that has recently been reported [15, 31,37], where the strain driven solid-state chemical reactions were facilitated by high impact milling [38-41]. The mechanochemical approach is very suitable for the synthesis of $\operatorname{IrB}_{2}$ compounds, as it is well known that the yield strength of iridium is $86.1 \mathrm{MPa}$ [42], which are well below the impact stress level produced during ball milling. The low yield strength of Ir, along with extended milling time, should allow for the synthesis of the desired compounds, which are impossible to produce by more traditional techniques. Thus, mechanochemical approaches to synthesis represent a promising route to the production of difficult to synthesize or even previously unknown ceramics. Additionally, this method has the capability of producing metastable compounds that cannot be easily processed by other available means. Here, we report our success in producing $\operatorname{IrB}_{2}$ and $\operatorname{IrB}$ phases mechanochemically.

\section{Experimental}


Iridium metal powder (Precious Metal Purchase, 99.9\% pure) and boron powder (Alfa Aesar, 99\% pure, -325 mesh, amorphous and crystalline) were used as starting materials. Highresolution synchrotron X-ray diffraction (XRD) pattern and scanning electron micrographs (SEM) of Ir powder used in the mechanochemical synthesis are shown in Fig. 3A and B, respectively. The high-resolution synchrotron XRD pattern, SEM and high resolution scanning transmission electron micrographs (STEM) of B powder are shown in Fig. 4A-C. A total of 11.7 grams of iridium and boron powders (molar ratio Ir:B=1:3) were loaded into a SPEX tungsten carbide vial with an internal volume of $54 \mathrm{~mL}$. Two $12.7 \mathrm{~mm}$ diameter tungsten carbide balls were used as milling media to produce a ball to powder weight ratio of 2.74 . All loading operations were carried out in an argon-filled glovebox. The milling vial and media were coated with iridium boron (boride) powders from an initial milling, which allows significant reduction of WC contamination, from the milling jar and media, in the Ir-B powders. The synthesis was performed by applying mechanical force with a SPEX 8000 Mixer/Mill for a total of 30 hours. The vials shake 1200 cycles per minute. Every 30 minutes the milling was interrupted and vials were left for 30 minutes without grinding in order to decrease the vials' temperature and reduce wear on the mill's motor. After 30 hours of milling, a small amount of sample was removed for phase analysis by XRD. One gram of the milled powder was taken from the vial, pressed into a small pellet and annealed in vacuo $(\sim 7 \mathrm{~Pa})$ in a quartz ampule at $1050^{\circ} \mathrm{C}$ for 48 hours. Collections of the ground powder were always performed in an argon-filled glovebox to control exposure to oxygen. After annealing, the phase compositions of the powders were analyzed by highresolution synchrotron XRD along with traditional laboratory XRD. A PANalytical X'Pert Pro MPD system with a copper source $(\mathrm{Cu} \mathrm{Kal}=1.5418 \AA)$ was used to record XRD patterns of the powder. High resolution powder XRD patterns were collected with synchrotron X-rays 
$(\lambda=0.4137 \AA)$ at the Advanced Photon Source (Beamline 11-BM), Argonne National Laboratory. The sample powders for synchrotron XRD were coated on capillary tubes to reduce absorption. Refinement of the structure was performed using the HighScore Plus software. The morphology and particle size of the powders were examined in a Zeiss Merlin SEM equipped with a silicon drift energy dispersive X-ray spectroscopy (EDS) detector capable of detecting low Z elements such as boron. A JEOL JEM2200FS aberration-corrected scanning transmission electron microscope was used to obtain high-resolution images of the iridium boride nanoparticles. The NETZSCH STA 449 F3 Jupiter ${ }^{\circledR}$ apparatus was used for DTA-TG measurements in $40 \mathrm{ml} / \mathrm{min}$ argon flow. Thermal analyses were performed up to $1400{ }^{\circ} \mathrm{C}$ with a heating rate of $10{ }^{\circ} \mathrm{C} / \mathrm{min}$. Alumina crucibles with $h$-BN protective film were used. The DTA-TG data presented in this paper has subtracted the BN baseline, which has no obvious peaks.

\section{Results and Discussion}

The laboratory XRD pattern of Ir-B powder taken immediately after 30 hours of ball milling is shown in Fig. 5A, where the diffractogram was taken right after the powder was removed from the milling container with the rest of powders collected and stored in an Ar-filled glovebox. The XRD pattern shows the presence of broad and overlapping peaks in the batch from which only two $\operatorname{IrB}_{1.1}$ and $\operatorname{IrB}_{1.35}$ phases were identified. As the peaks were broad and overlapping it was not possible to identify the presence of any other Ir-B phases after milling. Importantly, after 1 hour of exposure of the Ir-B powder to the air of the X-ray diffraction room peaks belonging to $\mathrm{H}_{3} \mathrm{BO}_{3}$ phase became identifiable and after 6 hours of dwell time at room temperature in air, the $\mathrm{H}_{3} \mathrm{BO}_{3}$ phase peaks became prominent (Fig. 5A). The time dependent appearance of boric acid peaks in an Ir-B batch after exposure to air is indeed an indicator that the surface of Ir-B powder is highly susceptible to the interactions with water vapor present in the environment, thus 
forming new compounds upon extended air exposure even at room temperature. As the resolution of the laboratory X-ray diffractometer was not very high, the Ir-B powder milled for 30 hours was examined using high-resolution synchrotron X-ray diffraction at the Advanced Photon Source, Argonne National Laboratory (Fig. 5B). Similar to the laboratory XRD results, only $\operatorname{IrB}_{1.1}$ and $\operatorname{IrB}_{1.35}$ phases were identified as being present by high-resolution synchrotron XRD. However, small peaks belonging to $\mathrm{H}_{3} \mathrm{BO}_{3}$ were also identified. As precautions were taken to protect the Ir-B powder from exposure to air, the first laboratory and high resolution synchrotron diffraction patterns can be compared and conclusions can be drawn that the possibility exists that the small quantities of water vapors were present on the surface of the powder even after the best efforts were taken to protect the material from exposure to air and humidity. However, since the resolution of the laboratory XRD is not high enough, such quantities simply cannot be detected (Fig. 5A) and the high-resolution synchrotron XRD is required to see the presence of $\mathrm{H}_{3} \mathrm{BO}_{3}$ (Fig. 5B).

The SEM micrograph of the Ir-B ceramic powder, after 30 hours of ball milling, showing that it consists of $3 \sim 5 \mu \mathrm{m}$ as well as large sizes agglomerates is presented in Fig. 6A. The EDS spectrum of the powder is shown in Fig. 6B, where both Ir and B elements along with small quantities of $\mathrm{W}$ and $\mathrm{C}$ indicating that $\mathrm{WC}$ media indeed contaminated the Ir-B ceramics during milling. As no peaks belonging to WC were identified in the XRD diffraction patterns, it is possible to conclude that WC formed a solid solution with Ir-B phases and does not exist as a separate phase in the batch. A peak of $\mathrm{O}$ is also present indicating that either $\mathrm{H}_{3} \mathrm{BO}_{3}$ or $\mathrm{B}_{2} \mathrm{O}_{3}$ phases exist on the surface of the powder.

In order to obtain more detailed information on the new material synthesized mechanochemically, a few small Ir-B agglomerates were imaged using TEM and their bright 
field micrographs are shown in Fig. 7A and B. As one can see from Fig. 7A and B, the size of the agglomerates varies from $\sim 0.5 \mu \mathrm{m}$ to above $2 \mu \mathrm{m}$ and the agglomerates consist of smaller crystallites representing single crystal particles with certain well defined crystallographic orientations (Fig. $7 \mathrm{C}$ and D). These crystallites agglomerate and form larger particles (shown in Fig. 7A and B). The random arrangement of crystal domains can be seen in the bright field HRSTEM micrographs in Fig. $7 \mathrm{E}$ and $\mathrm{F}$, where the lattice fringes with a $d$ spacing equal to 2.54 $\AA$ are separated by long defective stripes with a thickness of $0.8 \mathrm{~nm}$ (Fig. 7E), however at the dark field HRSTEM micrograph of the area only lattice fringes of Ir atoms can be seen (Fig. 7F). A significantly different type of agglomerate was also found, where the shape of the crystallites was more elongated, even needle-like. The bright-field STEM images of the agglomerates where elongated crystallites were found, along with higher resolution images of the elongated crystallites, are presented Fig.8. As one can see from Fig. 8 E and F, the length of one such crystallite can reach $20 \mathrm{~nm}$ while the width is only $2-3 \mathrm{~nm}$, thus, the aspect ratio of these needles could be 1:10 in thickness to length. The existence of such crystals might present an excellent opportunity to grow one dimensional (1D) nanostructures, such as nanowires or nano-belts, but more experimental and theoretical work would be required to better understand and, therefore, control the growth process of such Ir-B nanostructures.

In order to remove strain introduced during high energy ball milling and, at the same time, to improve crystallinity the Ir-B powder was annealed at $1050^{\circ} \mathrm{C}$ for 48 hours. The laboratory XRD pattern of the Ir-B powder after annealing is shown in Fig. 9A. As one can see from Fig. 9A, a mixture of three Ir-B phases is present in the batch after 30 hours of milling and 48 hours of annealing. Along with the $\operatorname{IrB}_{1.35}$ structure, a previously unreported $\operatorname{ReB}_{2}$-type $\operatorname{IrB}_{2}$ structure, as well as a new orthorhombic iridium monoboride (IrB) structure, have been identified. $\operatorname{ReB}_{2}{ }^{-}$ 
type $\operatorname{IrB}_{2}$ and orthorhombic $\operatorname{IrB}$ monoboride were found to be present by Rietveld refinement in only small quantities in comparison with the major $\operatorname{IrB}_{1.35}$ phase. It was found that the batch consisted of $76.2 \mathrm{wt} \% \operatorname{IrB}_{1.35}, 7.7 \mathrm{wt} \% \mathrm{ReB}_{2}$-type $\mathrm{IrB}_{2}$, and $16.1 \mathrm{wt} \%$ orthorhombic $\operatorname{IrB}$ phases. This information along with refined lattice parameters of the phases is presented in Table 1. The high-resolution synchrotron XRD pattern of the same Ir-B nanopowder after 48 hours of annealing is shown in Fig. 9B. Similar to the laboratory X-ray diffraction analysis, the same three Ir-B phases have been identified in the batch by Rietveld refinement but the quantities of the phases present were slightly different from the quantities of the phases measured by the laboratory diffractometer. As determined by synchrotron XRD, the major phase in the batch was $\mathrm{IrB}_{1.35}$ at $85.6 \mathrm{wt} \%$, while $\mathrm{ReB}_{2}$-type $\mathrm{IrB}_{2}$ phase was present in $9.2 \mathrm{wt} \%$, and orthorhombic $\operatorname{IrB}$ monoboride was identified to be $5.2 \mathrm{wt} \%$. The quantities of the phases as determined by synchrotron XRD source are also shown in Table 1 along with the data calculated by using the laboratory X-ray diffraction pattern. It should be noted that a significant difference in the relative wt $\%$ of IrB monoboride was observed between the two measurements. This discrepancy between the laboratory and synchrotron PXRD can be ascribed to the absorbing nature of the sample, especially at $\mathrm{CuKa}$ energies, and the differences in absorption of the constituents of the sample. This is further exacerbated by the differences in geometry in the experiments, i.e. flat plate vs. capillary. Due to this the values modeled from the synchrotron PXRD are more accurate, reliable and representative of the true sample composition. The lattice parameters of all phases present are also shown in Table 1 along with the lattice parameters of the phases predicted in the literature. The results of the Rietveld refinements are also listed in Table 1. While $\operatorname{IrB}_{1.35}$ and the $\mathrm{ReB}_{2}$-type $\mathrm{IrB}_{2}$ structure show a good correspondence between measured and predicted lattice 
parameters, the IrB phase, while possessing the structure predicted in [16], possesses lattice parameters significantly different from those predicted.

The bright field STEM micrographs of Ir-B powder after 30 hours of milling and 48 hours of annealing at $1050^{\circ} \mathrm{C}$ are shown in Fig. 10. All 6 STEM micrographs of powder shown in Fig. 10 represent different structures of Ir-B phases, as further identified by HRSTEM (Fig. 11 and 12). The Figure 10A represents the HRSTEM structure show in Fig. 11A and B and that particular structure might represent, in part, a non-reacted pure boron particle, where Fig. $11 \mathrm{~A}$ is a bright field STEM and Fig. 11B is a high angle annular dark field ( $\mathrm{Z}$ contrast) STEM image. The powder particle presented in Fig. 10B turn out to consist of many very tiny crystallites, as presented by bright and dark field STEM micrographs in Fig. $11 \mathrm{C}$ and D. The $\mathrm{ReB}_{2}$-type hexagonal $\mathrm{IrB}_{2}$ structure was found among the particles represented in Fig. 10C. The corresponding bright and dark field STEM images of the hexagonal $\operatorname{IrB}_{2}$ phase oriented in [100] direction are shown in HRSTEM (Fig. $11 \mathrm{E}$ and F). Three more different structures have been identified upon higher magnification of the Ir-B particles shown in Fig. 10 D-F. The bright and dark HRSTEM images (Fig. $12 \mathrm{~A}$ and B) of one of the particles shown in Fig. 10 D helped to identify a new IrB monoboride structure oriented along [131] zone axis. The same IrB structure but oriented along the [111] direction is shown in Fig. $12 \mathrm{C}$ and D. These high-resolution STEM micrographs were taken upon higher magnification of the Ir-B particle shown in Fig. 10 E. The $\operatorname{IrB}_{1.35}$ phase was identified in Fig. 10F with the bright and dark HRSTEM images of the $\operatorname{IrB}_{1.35}$ oriented along [010] direction shown in Fig. 12 E and F, respectively.

Thermogravimetry and DTA results taken during the heating of Ir-B powder after 30 hours of milling and 48 hours of annealing are presented in Fig. 13 A and B, respectively. The TG results show the weight gain during heating up to $\sim 1300^{\circ} \mathrm{C}$ or higher in both cases, which can be 
explained by the oxygen interaction with the powder with the formation of boron oxide all the way to the $1150-1220^{\circ} \mathrm{C}$ temperatures, where the DTA peak appears indicating the appearance of the phase transition. Such phase transition can be explained by the beginning of evaporation process of $\mathrm{B}_{2} \mathrm{O}_{3}$, which occurs at around $1244-1269^{\circ} \mathrm{C}$ for very fine powders. As evaporation process initiated, one can see the beginning of the weight loss of Ir-B powder, which is connected to the $\mathrm{B}$ and $\mathrm{O}$ atoms leaving the surface as vapors. The differences in the liquid to vapor phase transition temperature for the Ir-B powders with and without annealing can be explained that after annealing at $1050^{\circ} \mathrm{C}$ in vacuum the powder coarsened with particle sizes increased from $\sim 60 \mathrm{~nm}$ to $\sim 110 \mathrm{~nm}$ and such coarse particles were more resistant to oxidation and thus the evaporation temperature increased for the Ir-B powder after annealing.

\section{Conclusion}

Mechanochemistry is a very effective method for the synthesis of hard to produce boron rich Ir-B phases. As no iridium diborides have been reported in the past, the mechanochemical approach was effectively utilized in the synthesis of $\operatorname{ReB}_{2}$-type $\operatorname{IrB}_{2}$ phase. In addition to hexagonal $\mathrm{IrB}_{2}$ structure, a new orthorhombic $\operatorname{IrB}$ monoboride phase was also found. Evidence of severe interaction of Ir-B nanopowders with water vapor present in air was also noted, where under short exposure of Ir-B nanopowder to air resulted in formation of $\mathrm{H}_{3} \mathrm{BO}_{3}$ boric acid, even at room temperature. The heating of the Ir-B powder in Ar also confirmed the existence of interactions with even traces of oxygen resulting in the formation of the boron oxide on the surface of the powder during heating following with the liquid - gas phase transition upon reaching the evaporation temperature of $\mathrm{B}_{2} \mathrm{O}_{3}$ at $\sim 1200^{\circ} \mathrm{C}$.

\section{Acknowledgments}


This work was supported by NSF project DMR - 0748364. Electron microscopy was performed as part of a user project supported by ORNL's Center for Nanophase Materials Sciences (CNMS), which is a DOE Office of Science User Facility. Use of the Advanced Photon Source at Argonne National Laboratory was supported by the U. S. Department of Energy, Office of Science, Office of Basic Energy Sciences, under Contract No. DE-AC02-06CH11357. We would also like to thank the DEM Solution Academic Partner program for providing reduced cost access to DEM software, which was used for modeling of ball movement and stress distribution during high energy ball mill operation. 


\section{Figures}

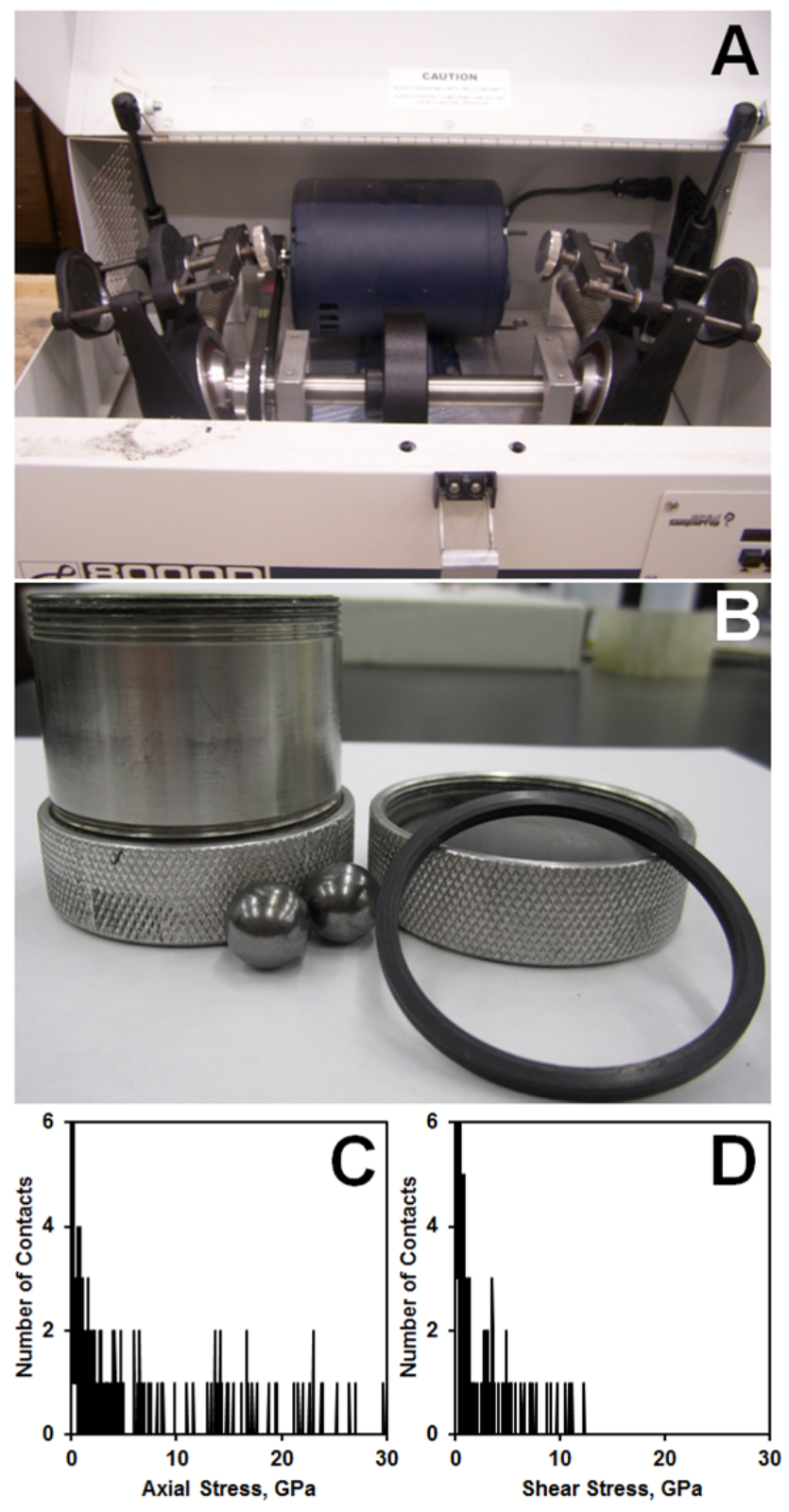

Fig. 1. A SPEX 8000D Mixer/Mill (A), WC milling vial set (B), and axial (C) and shear (D) stresses produced by the high energy ball milling according to the DEM simulation (EDEM). 

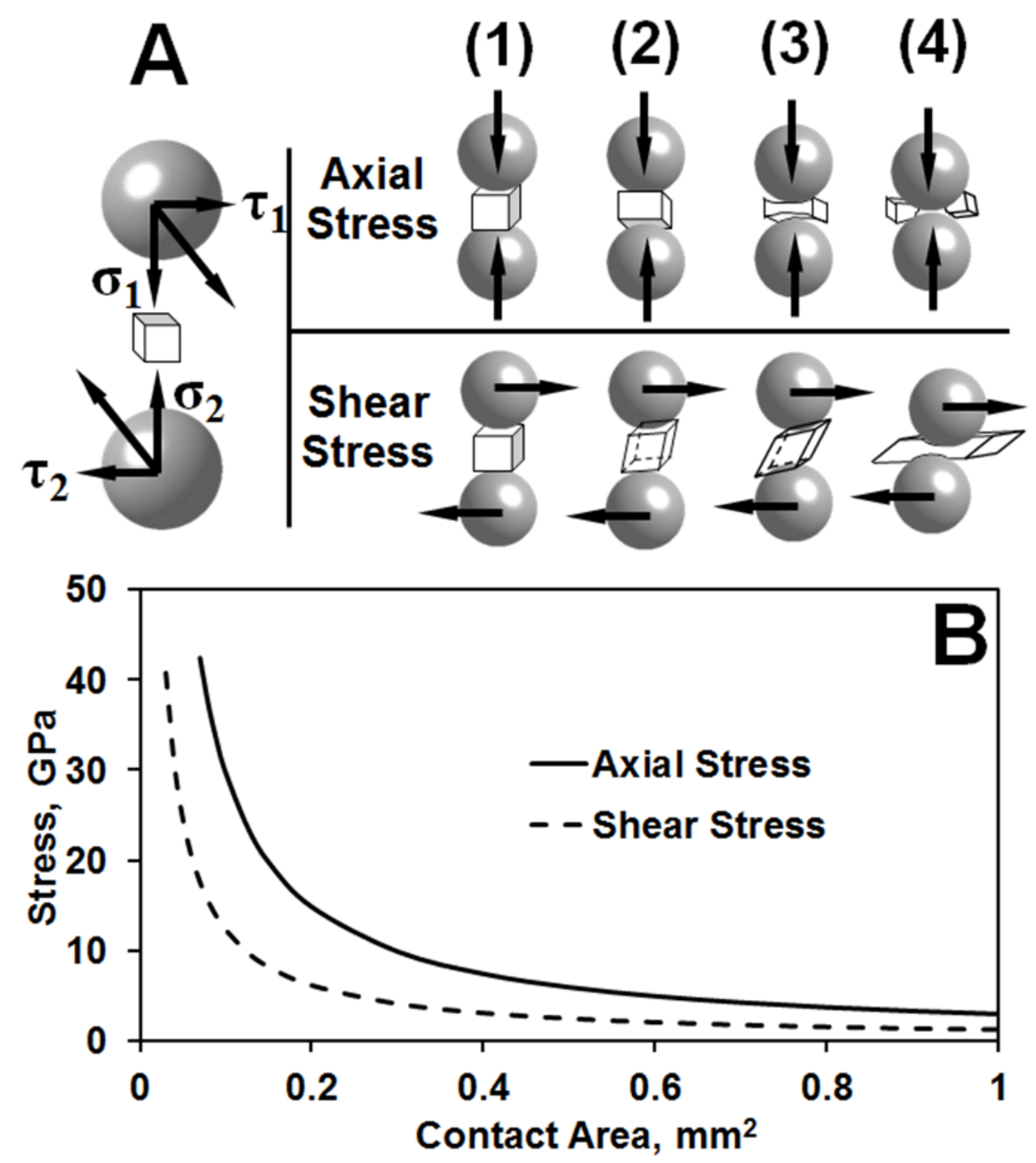

Fig. 2. Mechanism of high-energy ball milling (A), maximum axial and shear stresses present during mechanochemical synthesis of the Ir-B compound as a function of contact area (B). 


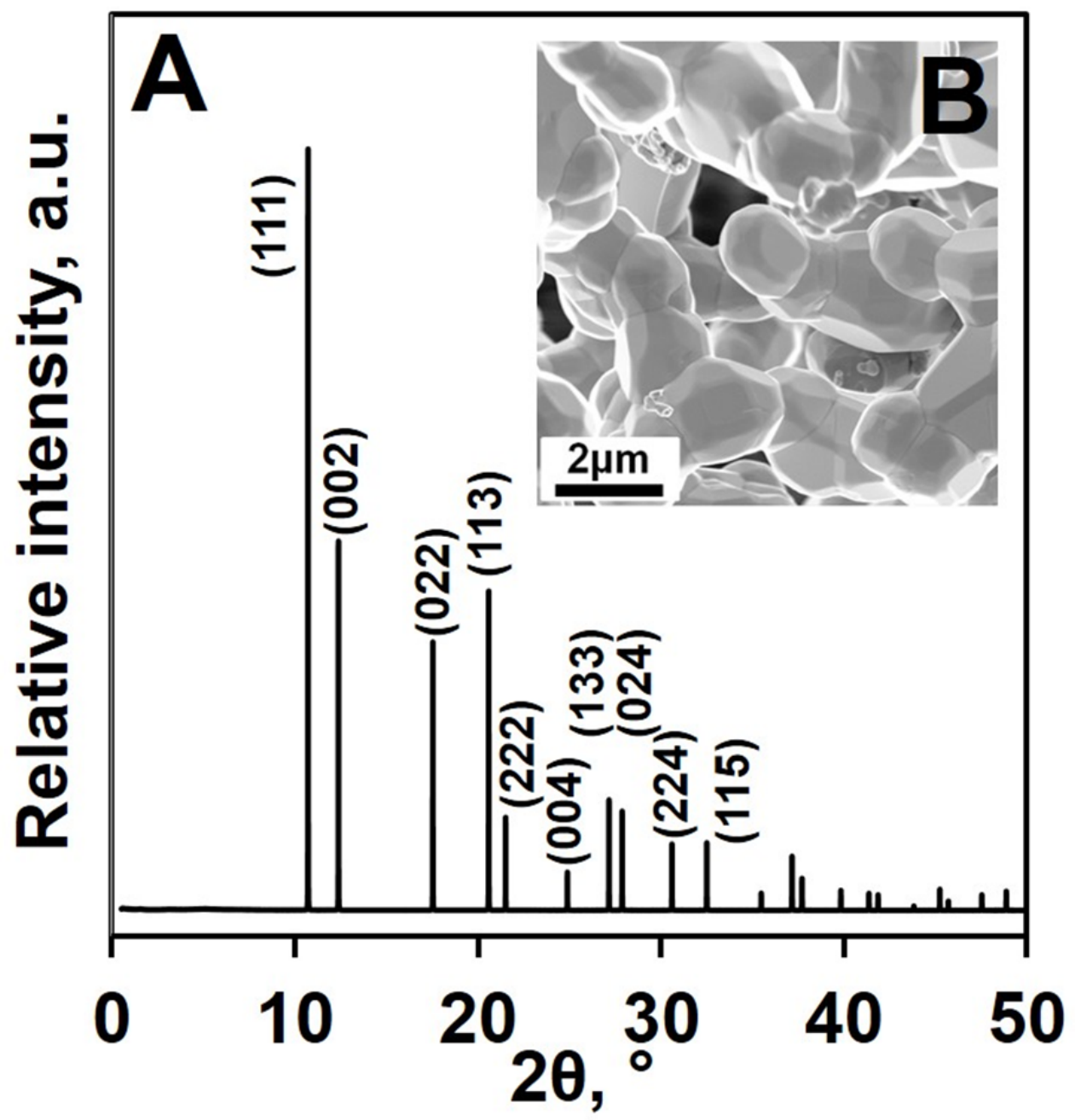

Fig. 3. Synchrotron XRD pattern (A) and SEM image (B) of raw iridium powder. 


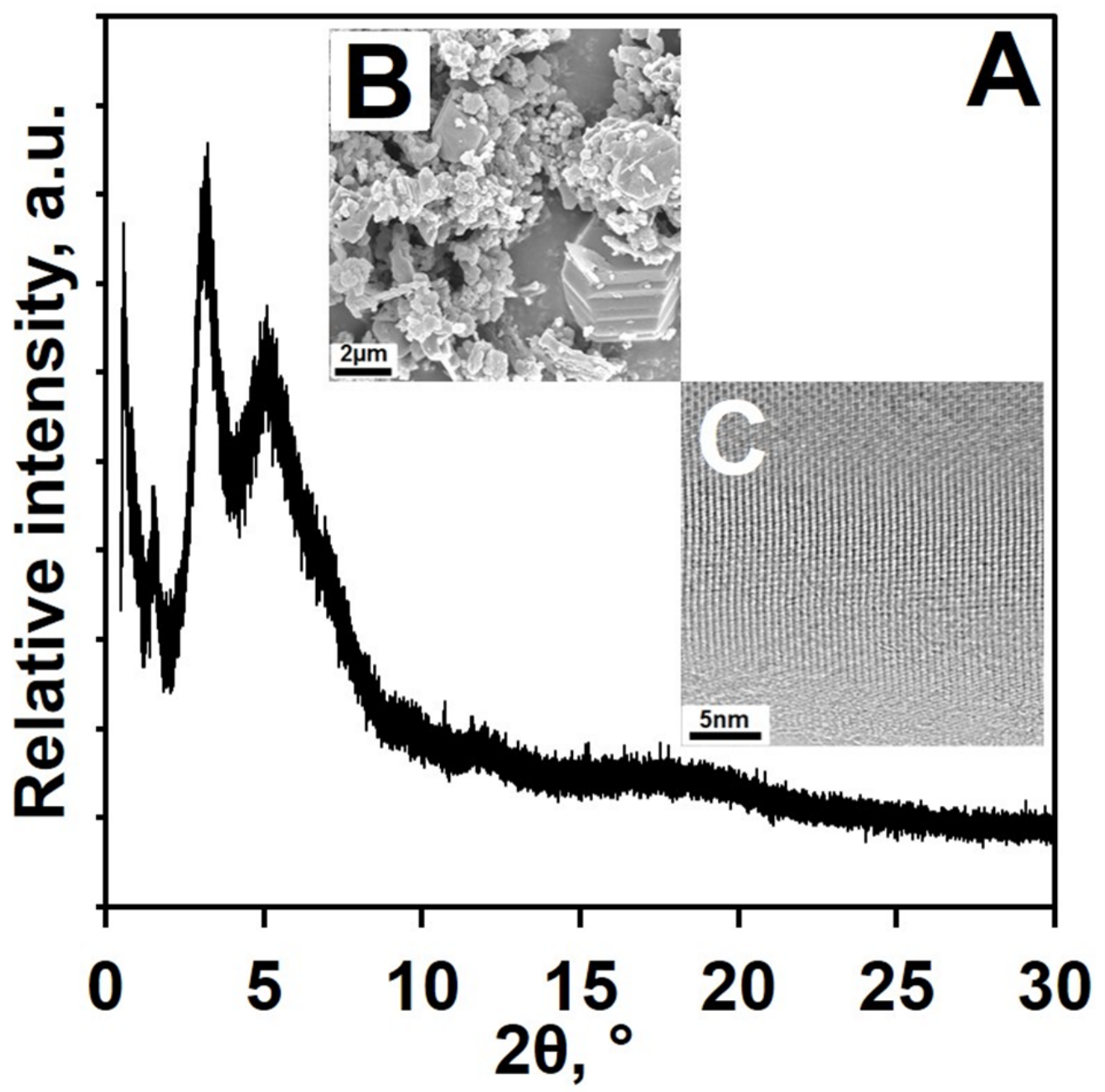

Fig. 4. Synchrotron XRD pattern (A), SEM (B) and bright-field STEM (C) images of raw boron powder. 

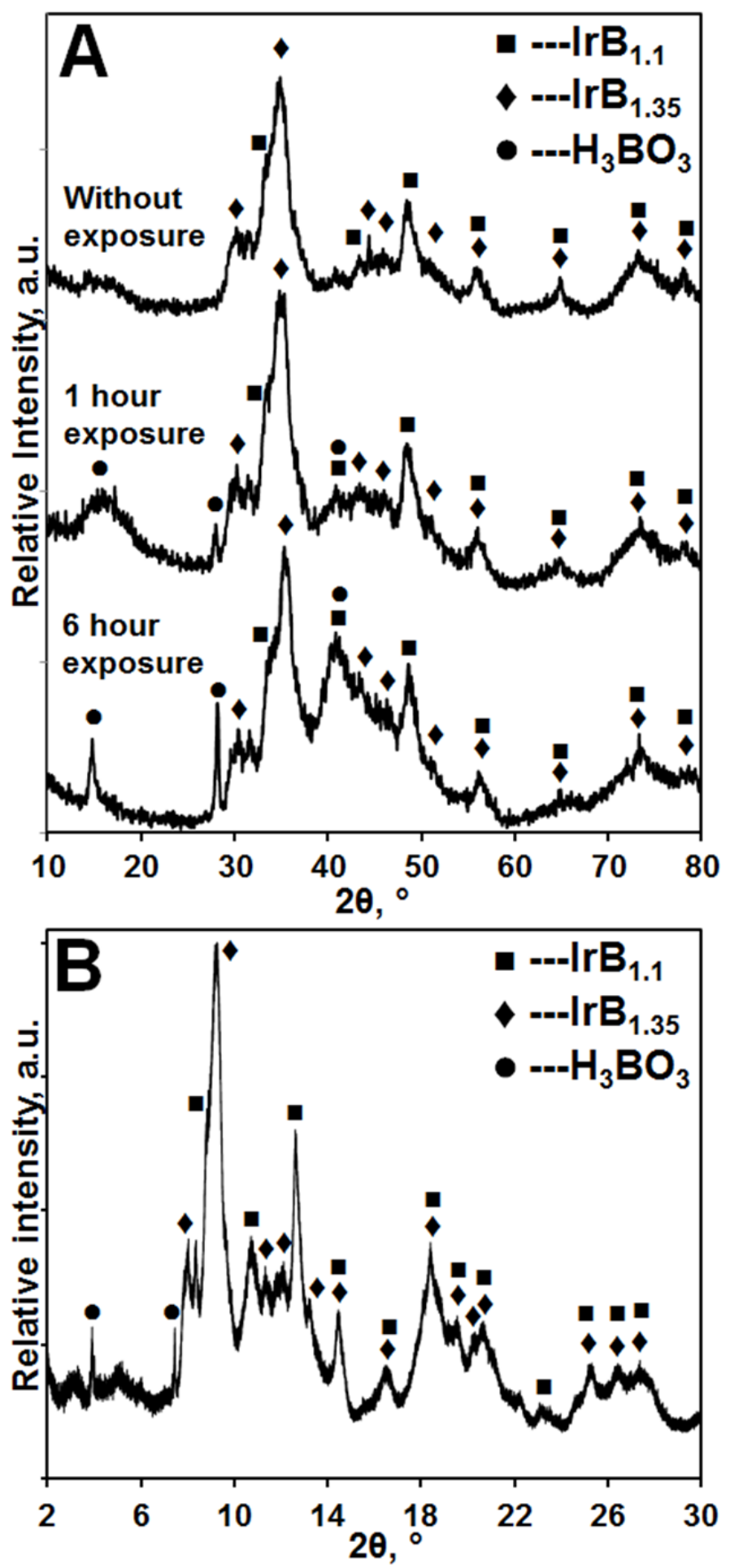

Fig. 5. XRD patterns of Ir and B powder mixture after 30 hours of ball milling and the corresponding time of exposure in air before XRD (A), and high resolution synchrotron XRD of Ir and B powder mixture after 30 hours of ball milling without exposure to air (B). 


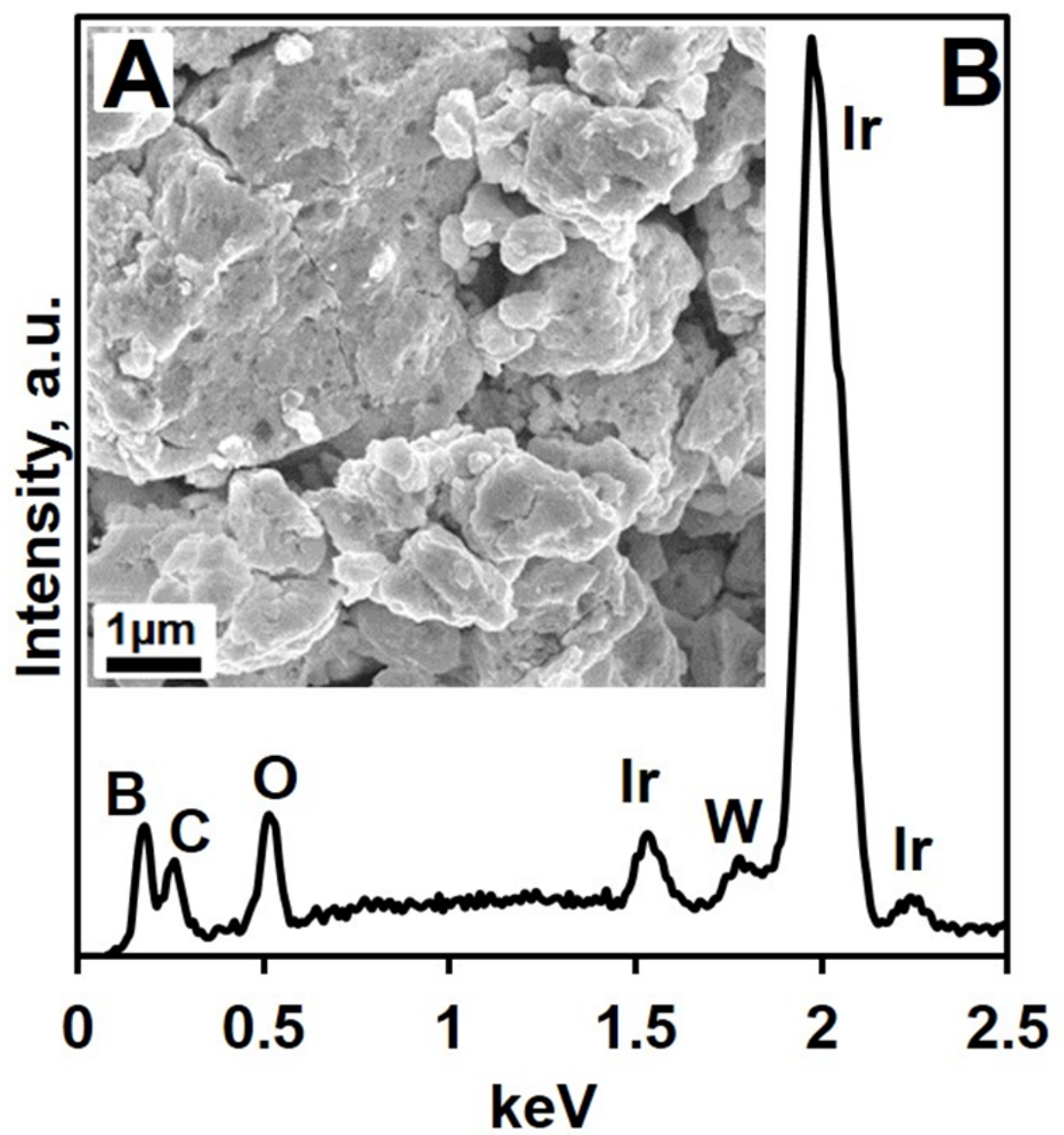

Fig. 6. SEM (A) and EDS (B) of Ir and B powder mixture after 30 hours of ball milling. 


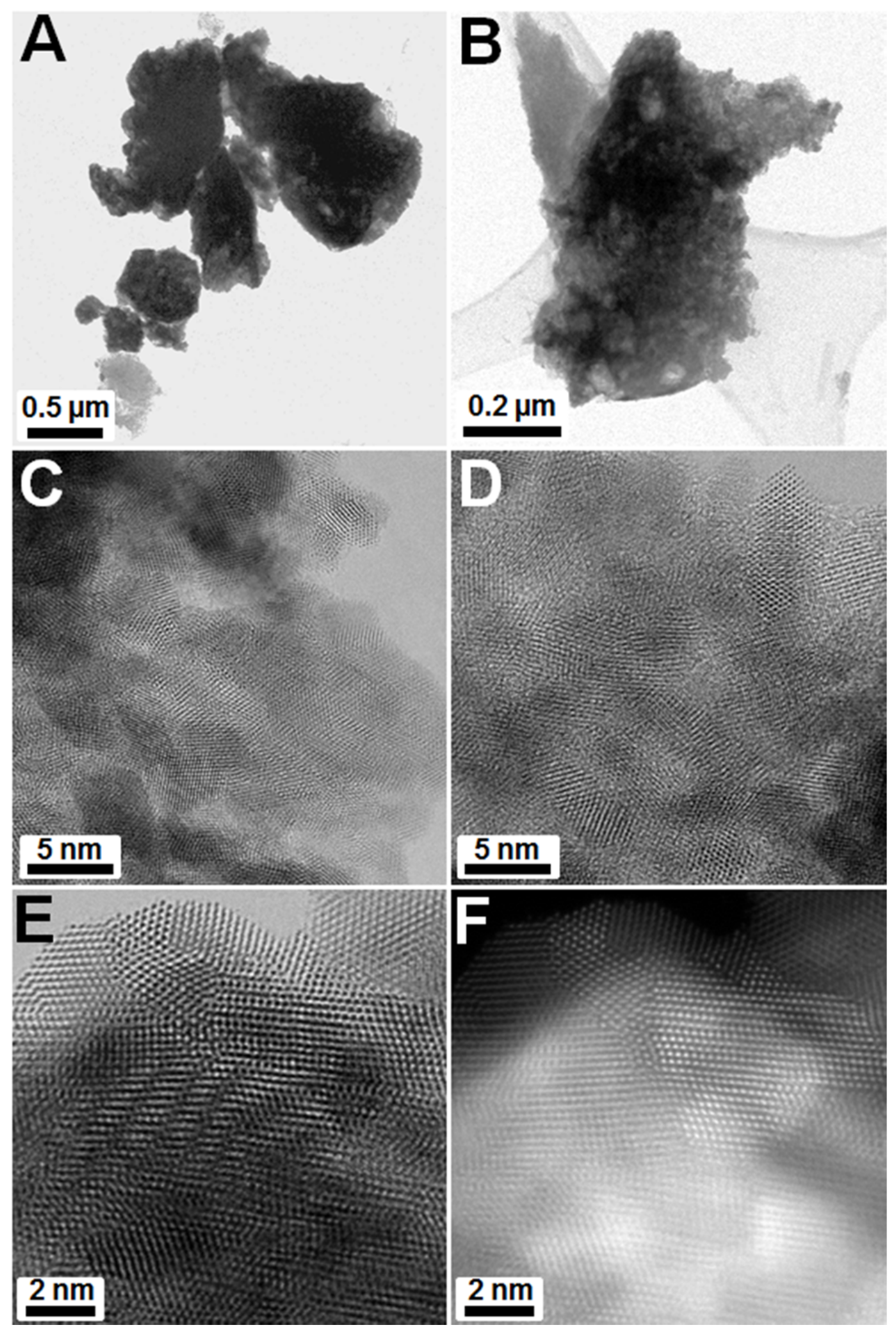

Fig. 7. Bright-field (A-E) and high-angle annular dark-field (F) STEM images of the Ir and B mixture after 30 hours of ball milling. 


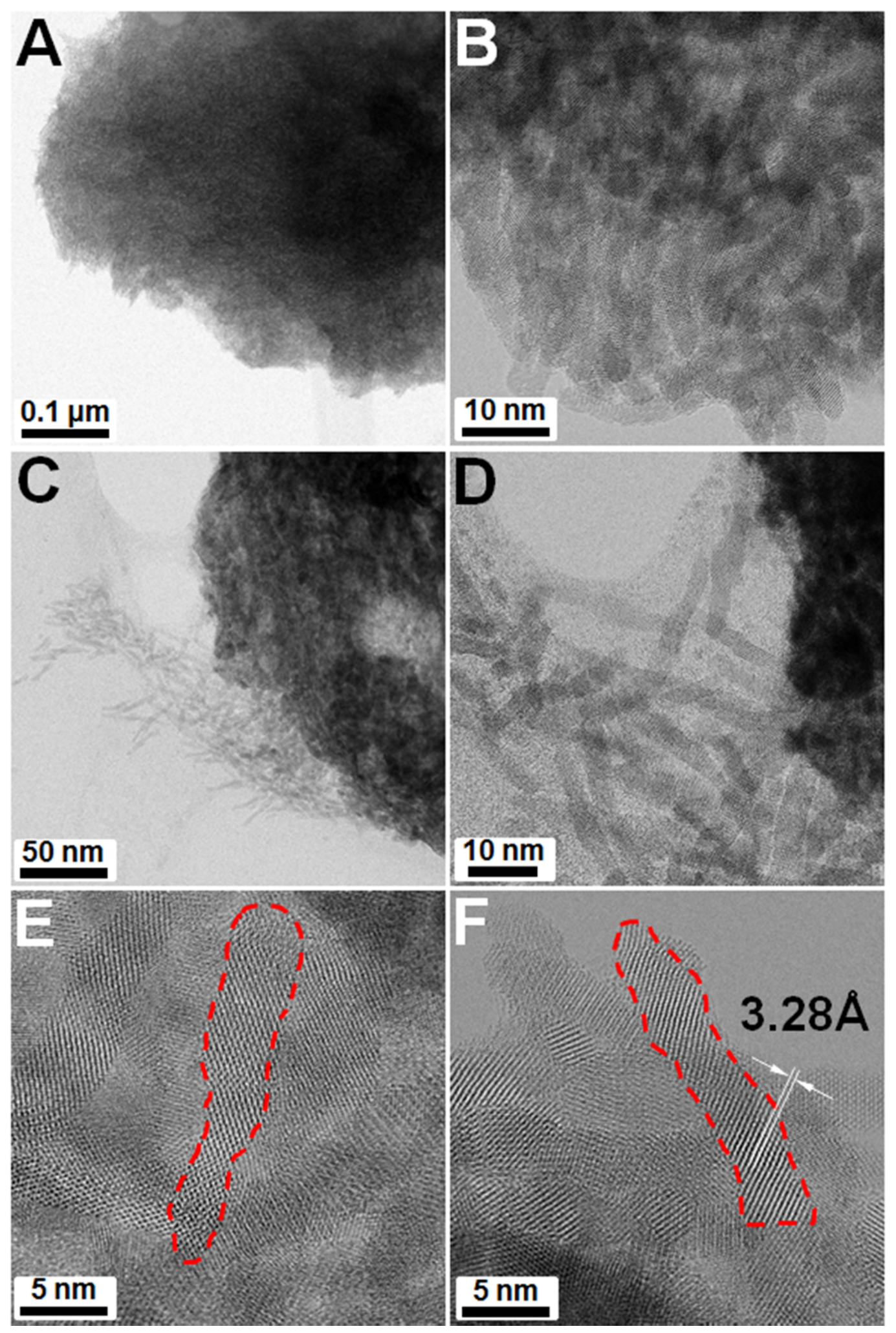

Fig. 8. Bright-field STEM images of the Ir and B mixture after 30 hours of ball milling showing regions of elongated particles. 

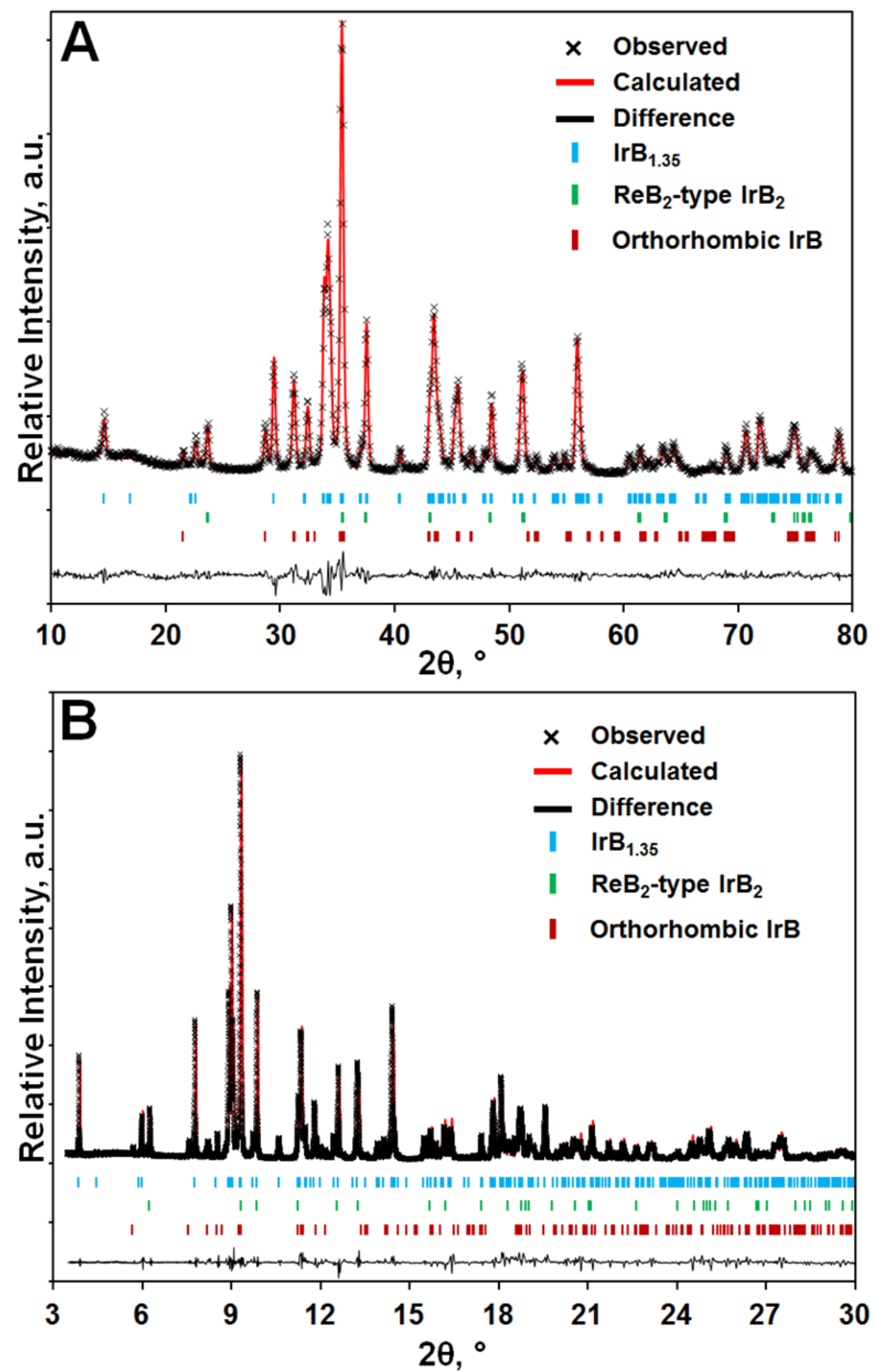

Fig. 9. Rietveld refinement of the X-ray diffractogram for the Ir and B powder mixture after 30 hours of ball milling and 48 hours of annealing with a laboratory XRD (A) and synchrotron source (B). Note that the X-ray wavelengths of the laboratory and synchrotron sources are different. Data plotted versus d space is available in supplemental materials. 


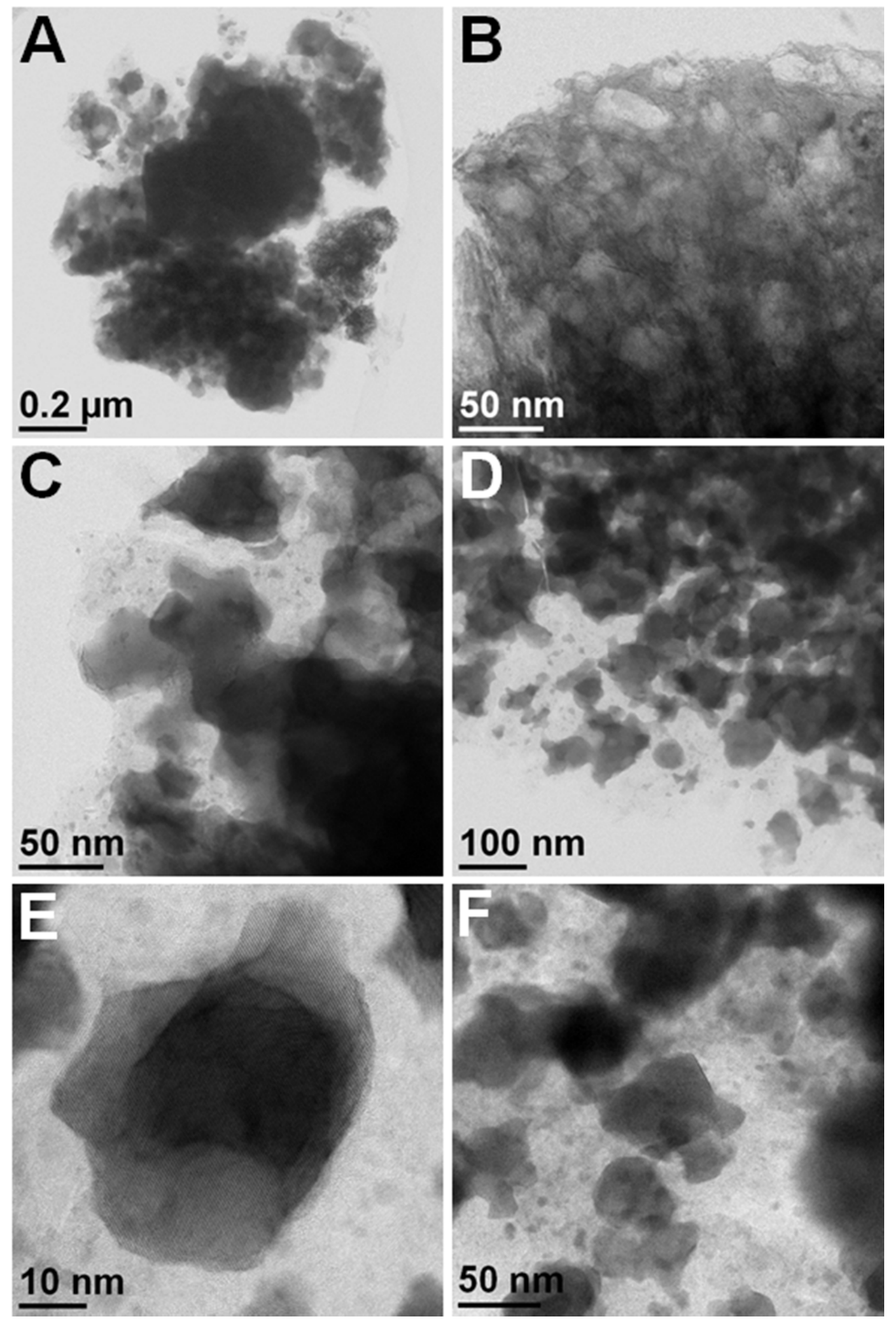

Fig. 10. STEM of the Ir and B mixture after 30 hours of ball milling and 48 hours of annealing. 

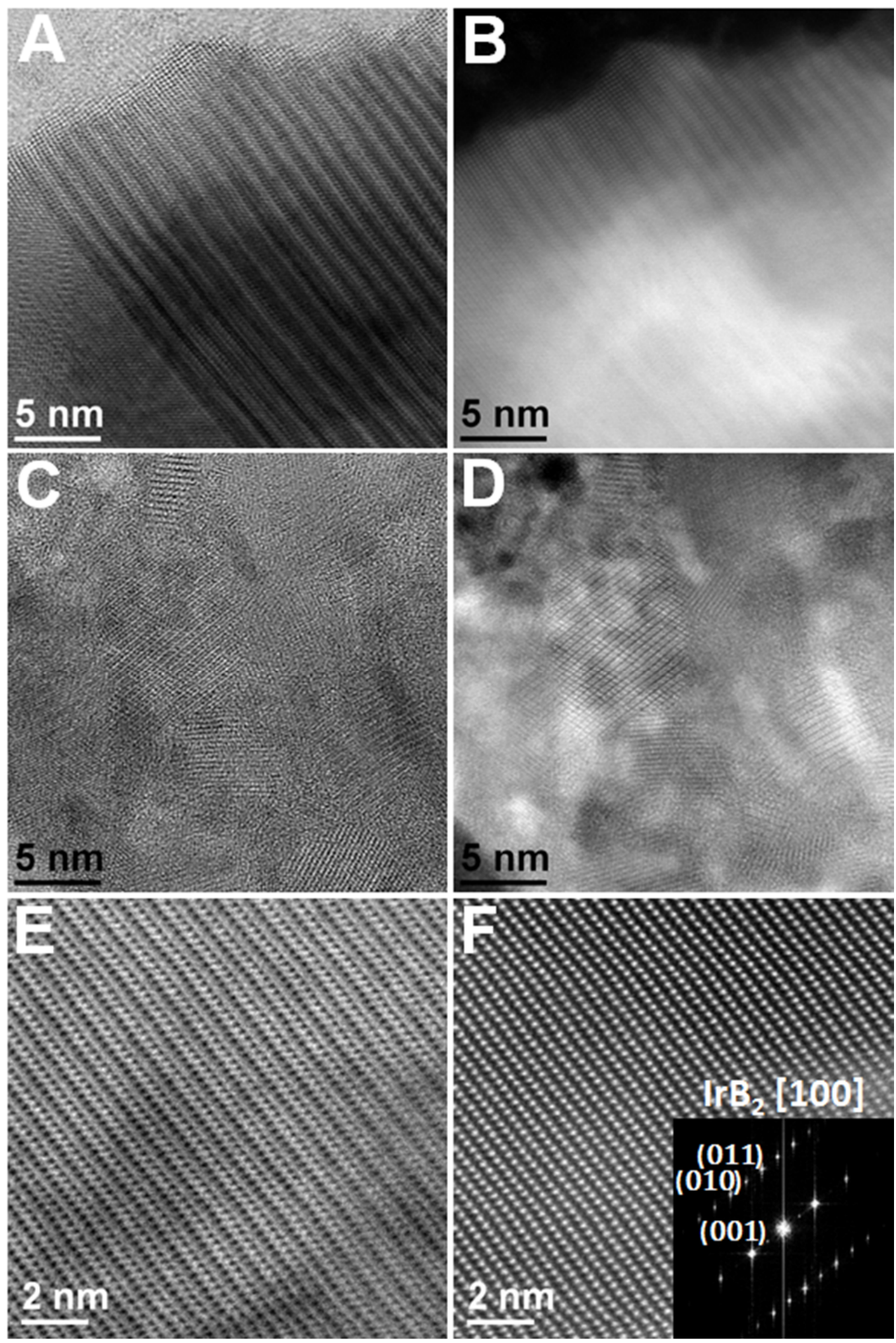

Fig. 11. STEM of the Ir and B mixture after 30 hours of ball milling and 48 hours of annealing. 

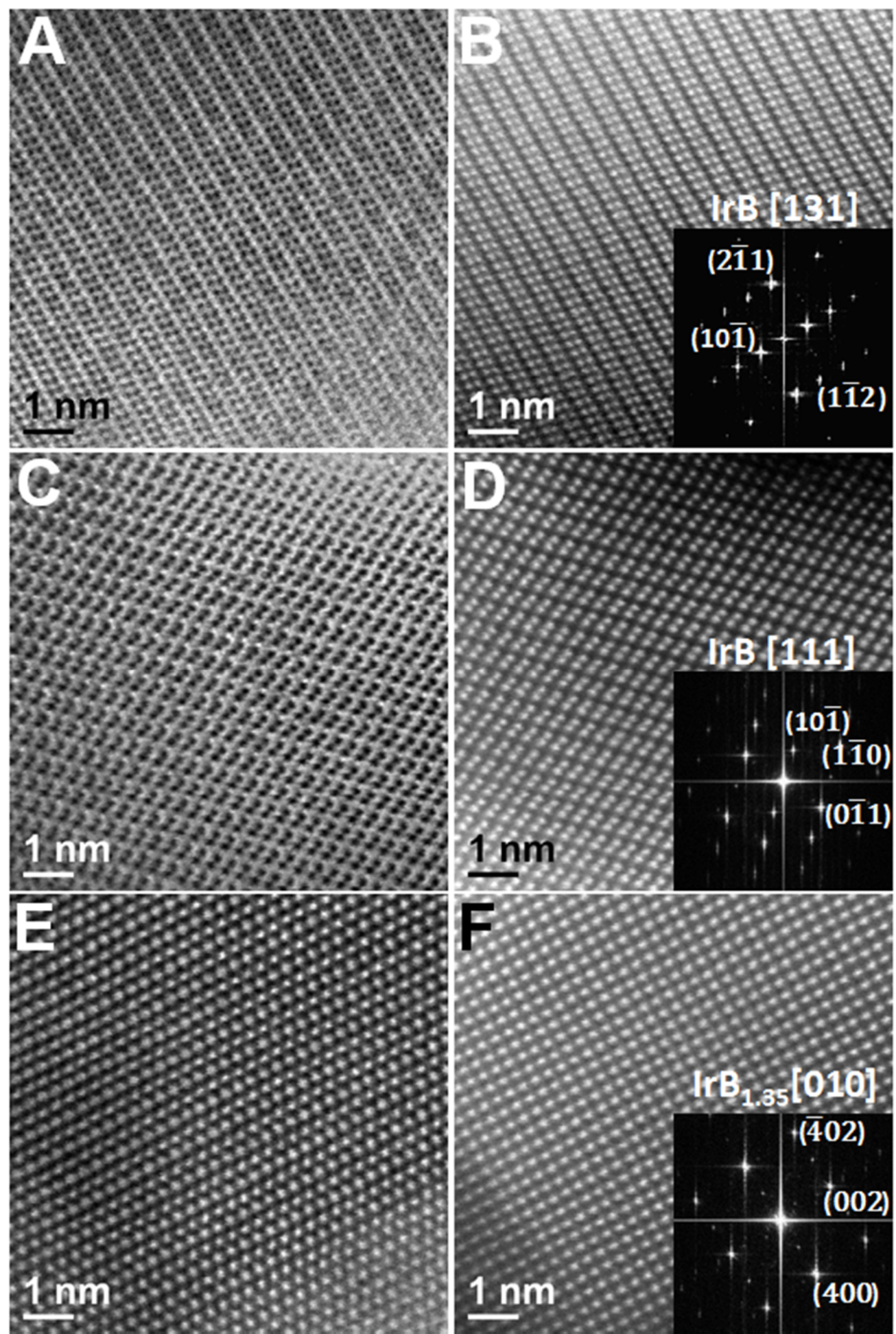

Fig. 12. High resolution STEM of the Ir and B mixture after 30 hours of ball milling and 48 hours of annealing. 

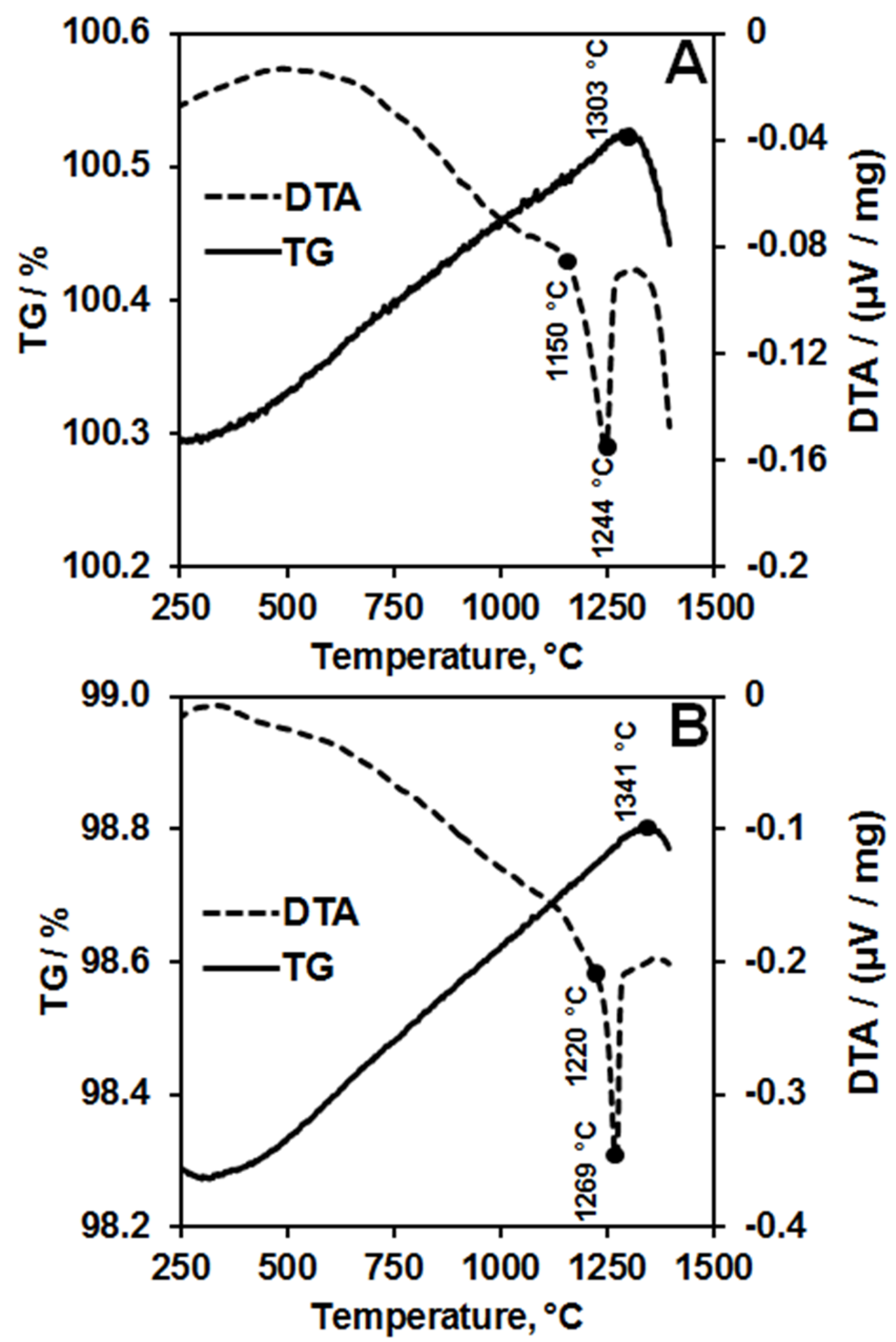

Figure 13. Thermogravimetric and differential thermal analysis of Ir-B powder mixture after $30 \mathrm{~h}$ milling (A), and Ir-B powder mixture after $30 \mathrm{~h}$ milling and $48 \mathrm{~h}$ annealing (B). 
Table 1. Lattice parameters and weight fraction of each phase in the Ir-B mixture after ball milling for 30 hour and annealing for 48 hours based on the refinement of XRD patterns. Numbers in parentheses are statistical deviations in the last significant digit. $R_{B r a g g}, R_{F}, R_{p}, R_{w p}$, $\mathrm{R}_{\mathrm{exp}}$ and $\chi^{2}$ correspond to Bragg, crystallographic $\mathrm{R}_{\mathrm{F}}$ factor, profile and weighted profile residuals, expected residual and goodness of fit, respectively.

\begin{tabular}{|c|c|c|c|c|c|c|c|c|c|}
\hline & \multirow{2}{*}{ Ir-B phases } & \multicolumn{4}{|c|}{ Lattice parameters } & \multirow{2}{*}{$\mathrm{R}_{\text {Bragg }}, \%$} & \multirow{2}{*}{$\mathrm{R}_{\mathrm{F}}, \%$} & \multirow{2}{*}{$\begin{array}{l}\text { Overall fit } \\
\text { residuals }\end{array}$} & \multirow{2}{*}{$\begin{array}{c}\text { Weight } \\
\text { fraction, \% }\end{array}$} \\
\hline & & $a, \AA$ & $b, \AA$ & $c, \AA$ & $\beta,{ }^{\circ}$ & & & & \\
\hline \multirow{3}{*}{$\begin{array}{c}\text { Refinement } \\
\text { of } \\
\text { laboratory } \\
\text { XRD } \\
\text { pattern }\end{array}$} & $\mathrm{IrB}_{1.35}$ & $10.5245(9)$ & $2.8967(2)$ & $6.0848(6)$ & $91.046(7)$ & 3.83 & 3.07 & \multirow{3}{*}{$\begin{aligned} \mathrm{R}_{\mathrm{p}} & =7.17 \% \\
\mathrm{R}_{\mathrm{wp}} & =9.44 \% \\
\mathrm{R}_{\exp } & =3.96 \% \\
\chi^{2} & =5.67\end{aligned}$} & 76.2 \\
\hline & $\begin{array}{c}\mathrm{ReB}_{2} \text {-type } \\
\mathrm{IrB}_{2}\end{array}$ & $2.9260(5)$ & $2.9260(5)$ & $7.543(2)$ & - & 4.05 & 3.88 & & 7.7 \\
\hline & $o$-IrB & $5.5407(9)$ & $3.2387(5)$ & $6.239(1)$ & - & 5.44 & 3.66 & & 16.1 \\
\hline \multirow{3}{*}{$\begin{array}{l}\text { Refinement } \\
\text { of } \\
\text { synchrotron } \\
\text { XRD } \\
\text { pattern } \\
\end{array}$} & $\mathrm{IrB}_{1.35}$ & $10.530(1)$ & $2.8978(3)$ & $6.0857(7)$ & $91.047(8)$ & 3.11 & 2.92 & \multirow{3}{*}{$\begin{aligned} \mathrm{R}_{\mathrm{p}} & =3.43 \% \\
\mathrm{R}_{\mathrm{wp}} & =6.31 \% \\
\mathrm{R}_{\text {exp }} & =3.37 \% \\
\chi^{2} & =3.50\end{aligned}$} & 85.6 \\
\hline & $\begin{array}{c}\text { ReB }{ }_{2} \text {-type } \\
\mathrm{IrB}_{2} \\
\end{array}$ & $2.9257(6)$ & $2.9257(6)$ & $7.547(2)$ & - & 2.76 & 2.54 & & 9.2 \\
\hline & $o$-IrB & $5.544(1)$ & $3.2443(7)$ & $6.242(1)$ & - & 2.33 & 2.21 & & 5.2 \\
\hline \multirow{3}{*}{$\begin{array}{c}\text { Other } \\
\text { experimenta } \\
\text { lly reported } \\
\text { or } \\
\text { calculated } \\
\text { parameters }\end{array}$} & $\operatorname{IrB}_{1.35}[43]$ & 10.525 & 2.910 & 6.099 & 91.0 & - & - & - & - \\
\hline & $\begin{array}{c}\mathrm{ReB}_{2} \text {-type } \\
\mathrm{IrB}_{2}[16] \\
\end{array}$ & 3.071 & 3.071 & 7.078 & - & - & - & - & - \\
\hline & $o$-IrB [16] & 4.428 & 2.870 & 7.021 & - & - & - & - & - \\
\hline
\end{tabular}




\section{References}

[1] R. G. Munro, "Material Properties of Titanium Diboride" J. Res. Natl. Inst. Stand. Technol., vol. 105, pp. 709-720, 2000.

[2] E. Eakins, D. Jayaseelan, and W. Lee, "Toward Oxidation-Resistant $\mathrm{ZrB}_{2}-\mathrm{SiC}$ Ultra High Temperature Ceramics" Metallurgical and Materials Transactions A, vol. 42, pp. 878887, 2011/04/01 2011.

[3] J. K. Sonber and A. K. Suri, "Synthesis and consolidation of zirconium diboride: review" Advances in Applied Ceramics, vol. 110, pp. 321-334, 2011.

[4] N. Orlovskaya, R. Stadelmann, M. Lugovy, V. Subbotin, G. Subhash, M. Neubert, et al., "Mechanical properties of $\mathrm{ZrB}_{2}-\mathrm{SiC}$ ceramic composites: room temperature instantaneous behaviour" Advances in Applied Ceramics, vol. 112, pp. 9-16, 2013.

[5] M. Jalaly, M. Sh. Bafghi, M. Tamizifar, and F. J. Gotor, "Mechanosynthesis of nanocrystalline $\mathrm{ZrB}_{2}$-based powders by mechanically induced self-sustaining reaction method" Advances in Applied Ceramics, vol. 112, pp. 383-388, 2013.

[6] W. G. Fahrenholtz, G. E. Hilmas, I. G. Talmy, and J. A. Zaykoski, "Refractory Diborides of Zirconium and Hafnium" Journal of the American Ceramic Society, vol. 90, pp. 13471364, 2007.

[7] B. Cristina and Y. Tsutomu, "Review of the superconducting properties of $\mathrm{MgB}_{2}$ " Superconductor Science and Technology, vol. 14, p. R115, 2001.

[8] X. Fan, X. Xiao, L. Chen, J. Shao, L. Zhang, S. Li, et al., "Superior Catalytic Effects of Transition Metal Boride Nanoparticles on the Reversible Hydrogen Storage Properties of Li-Mg-B-H System" Particle \& Particle Systems Characterization, vol. 31, pp. 195-200, 2014.

[9] H.-Y. Chung, M. B. Weinberger, J. B. Levine, A. Kavner, J.-M. Yang, S. H. Tolbert, et al., "Synthesis of Ultra-Incompressible Superhard Rhenium Diboride at Ambient Pressure" Science, vol. 316, pp. 436-439, April 20, 20072007.

[10] R. W. Cumberland, M. B. Weinberger, J. J. Gilman, S. M. Clark, S. H. Tolbert, and R. B. Kaner, "Osmium Diboride, An Ultra-Incompressible, Hard Material" Journal of the American Chemical Society, vol. 127, pp. 7264-7265, 2005/05/01 2005.

[11] H.-Y. Chung, J. M. Yang, S. H. Tolbert, and R. B. Kaner, "Anisotropic mechanical properties of ultra-incompressible, hard osmium diboride" Journal of Materials Research, vol. 23, pp. 1797-1801, 2008.

[12] A. Latini, J. V. Rau, R. Teghil, A. Generosi, and V. R. Albertini, "Superhard Properties of Rhodium and Iridium Boride Films" ACS Applied Materials \& Interfaces, vol. 2, pp. 581-587, 2010/02/24 2010. 
[13] A. Knappschneider, C. Litterscheid, J. Kurzman, R. Seshadri, and B. Albert, "Crystal Structure Refinement and Bonding Patterns of $\mathrm{CrB}_{4}$ : A Boron-Rich Boride with a Framework of Tetrahedrally Coordinated B Atoms" Inorganic Chemistry, vol. 50, pp. 10540-10542, 2011/11/07 2011.

[14] R. Mohammadi, A. T. Lech, M. Xie, B. E. Weaver, M. T. Yeung, S. H. Tolbert, et al., "Tungsten tetraboride, an inexpensive superhard material" Proceedings of the National Academy of Sciences, June 20, 20112011.

[15] Z. Xie, M. Lugovy, N. Orlovskaya, T. Graule, J. Kuebler, M. Mueller, et al., "Hexagonal $\mathrm{OsB}_{2}$ : Sintering, microstructure and mechanical properties" Journal of Alloys and Compounds, vol. 634, pp. 168-178, 6/15/2015.

[16] D. Y. Wang, B. Wang, and Y. X. Wang, "New Crystal Structures of $\operatorname{IrB}$ and $\operatorname{IrB}_{2}$ : FirstPrinciples Calculations" The Journal of Physical Chemistry C, vol. 116, pp. 21961-21966, 2012/10/18 2012.

[17] B. Aronsson, E. Stenberg, and J. Aselius, "Borides of Rhenium and the Platinum Metals" Acta Chemica Scandinavica, vol. 14, 1960.

[18] B. Aronsson, E. Stenberg, and J. Aselius, "Borides of Ruthenium, Osmium and Iridium," Nature, vol. 195, pp. 377-378, 1962.

[19] B. Aronsson, "The Crystal Structure of $\mathrm{RuB}_{2}, \mathrm{OsB}_{2}$, and $\operatorname{IrB}_{1.35}$ and Some General Comments on the Crystal Chemistry of Borides in the Composition Range MeB - $\mathrm{MeB}_{3}$ " Acta Chemica Scandinavica, vol. 17, 1963.

[20] P. Rogl, H. Nowotny, and F. Benesovsky, "Ein Beitrag zur Strukturchemie der Iridiumboride" Monatshefte für Chemie / Chemical Monthly, vol. 102, pp. 678-686, 1971/05/01 1971.

[21] B. Aronsson and S. Rundqvist, "Borides, Silicides and Phosphicles of the Platinum Metals" Platinum Metals Rev.,, vol. 5, pp. 93-95, 1961.

[22] Z. Xie, A. C. Terracciano, D. A. Cullen, R. G. Blair, and N. Orlovskaya, "High Temperature Ir Segregation in Ir-B Ceramics: Effect of Oxygen Presence on Stability of $\mathrm{IrB}_{2}$ and Other Ir-B Phases" Advances in Applied Ceramics, p. 1743676115Y.0000000002, 2015.

[23] I. Zeiringer, P. Rogl, A. Grytsiv, J. Polt, E. Bauer, and G. Giester, "Crystal Structure of WB and Phase Equilibria in the Boron-Rich Part of the Systems Mo-Rh-B and W$\{\mathrm{Ru}, \mathrm{Os}, \mathrm{Rh}, \mathrm{Ir}, \mathrm{Ni}, \mathrm{Pd}, \mathrm{Pt}\}-\mathrm{B} "$ Journal of Phase Equilibria \& Diffusion, vol. 35, pp. 384-395, 2014.

[24] P. Rogl, H. Nowotny, and F. Benesovsky, "Ternäre Komplexboride in den Dreistoffen: $\{\mathrm{Mo}, \mathrm{W}\}-\{\mathrm{Ru}, \mathrm{Os}\}-\mathrm{B}$ und W-Ir-B" Monatshefte für Chemie / Chemical Monthly, vol. 101, pp. 850-854, 1970/05/01 1970. 
[25] J. V. Rau and A. Latini, "New Hard and Superhard Materials: $\operatorname{RhB}_{1.1}$ and $\operatorname{IrB}_{1.35}$ " Chemistry of Materials, vol. 21, pp. 1407-1409, 2009/04/28 2009.

[26] W. J. Zhao and Y. X. Wang, "Structural, mechanical, and electronic properties of $\mathrm{TaB}_{2}$, $\mathrm{TaB}, \mathrm{IrB}_{2}$, and IrB: First-principle calculations" Journal of Solid State Chemistry, vol. 182, pp. 2880-2886, 10// 2009.

[27] Dragana Živković and L. Stuparevic, "Calculation of the thermodynamic properties in the Ir-B system based on the known phase diagram" RMZ-Materials and Geoenvironment, vol. 52, pp. 463-468, 2005.

[28] G. F. Tavadze and A. S. Shteinberg, Production of advanced materials by methods of self-propagating high-temperature synthesis: Springer, 2013.

[29] Z.-W. Ji, C.-H. Hu, D.-H. Wang, Y. Zhong, J. Yang, W.-Q. Zhang, et al., "Mechanical properties and chemical bonding of the Os-B system: A first-principles study" Acta Materialia, vol. 60, pp. 4208-4217, 6// 2012.

[30] N. Orlovskaya, Z. Xie, M. Klimov, H. Heinrich, D. Restrepo, R. Blair, et al., "Mechanochemical synthesis of $\mathrm{ReB}_{2}$ powder" Journal of Materials Research, vol. 26, pp. 2772-2779, 2011.

[31] Z. Xie, M. Graule, N. Orlovskaya, E. Andrew Payzant, D. A. Cullen, and R. G. Blair, "Novel high pressure hexagonal $\mathrm{OsB}_{2}$ by mechanochemistry" Journal of Solid State Chemistry, vol. 215, pp. 16-21, 7// 2014.

[32] Z. Xie, R. Blair, N. Orlovskaya, and E. A. Payzant, "Hexagonal $\mathrm{OsB}_{2}$ reduction upon heating in $\mathrm{H} 2$ containing environment" Advances in Applied Ceramics, vol. In press, 2014.

[33] Z. Xie, R. G. Blair, N. Orlovskaya, D. A. Cullen, and E. Andrew Payzant, "Thermal stability of hexagonal $\mathrm{OsB}_{2}$ " Journal of Solid State Chemistry, vol. 219, pp. 210-219, 11// 2014.

[34] D. Gugan, "Inelastic collision and the Hertz theory of impact" Am. F. Phys., vol. 68, pp. 920-924, 2000.

[35] P. van Dijk, "Contact Spots" in 20th Conference on Electrical Contacts, 2000.

[36] DEMSolutions, "EDEM" in http://www.dem-solutions.com/, ed, 2015.

[37] N. Orlovskaya, Z. Xie, and R. Blair, "Mechanochemical Synthesis of Hexagonal $\mathrm{OsB}_{2}$ " U.S. Patent, vol. 14/157,216, 2014.

[38] C. Suryanarayana, "Mechanical alloying and milling" Progress in Materials Science, vol. 46, pp. 1-184, 1// 2001. 
[39] C. Suryanarayana, E. Ivanov, and V. V. Boldyrev, "The science and technology of mechanical alloying" Materials Science and Engineering: A, vol. 304-306, pp. 151-158, $5 / 31 / 2001$.

[40] J. J. Gilman, "Mechanochemistry" Science, vol. 274, p. 65, October 4, 19961996.

[41] V. I. Levitas, "Continuum mechanical fundamentals of mechanochemistry" in High Pressure Surface Science and Engineering, ed: Taylor \& Francis, 2003, pp. 161-292.

[42] C. T. Liu and H. Inouye, "Study of iridium and iridium--tungsten alloys for space radioisotopic heat sources. [Up to $4 \% \mathrm{~W}$; fabrication; microstructure; tensile; oxidation; compatibility; fractures]" ORNL-5240; TRN: 77-005712 United States10.2172/7321970TRN: 77-005712Thu Jun 28 09:03:31 EDT 2012Dep. NTISORNL; ERA-02-022798; EDB-77-043558English, 1976.

[43] "Powder Diffraction File 2, database JCPDS CARDs: 17-0371 and 73-1845; International Centre for Diffraction Data: Newtown Square, PA." 


\section{Graphical abstract}

$\mathrm{ReB}_{2}$-type $\operatorname{IrB}_{2}$ and a new $\operatorname{IrB}$ have been successfully synthesized for the first time using mechanochemical method. Crystal structures of $\operatorname{IrB}_{2}$ and $\operatorname{IrB}$ were studied by synchrotron X-ray diffraction. Microstructures of the new phases were characterized by SEM and TEM.

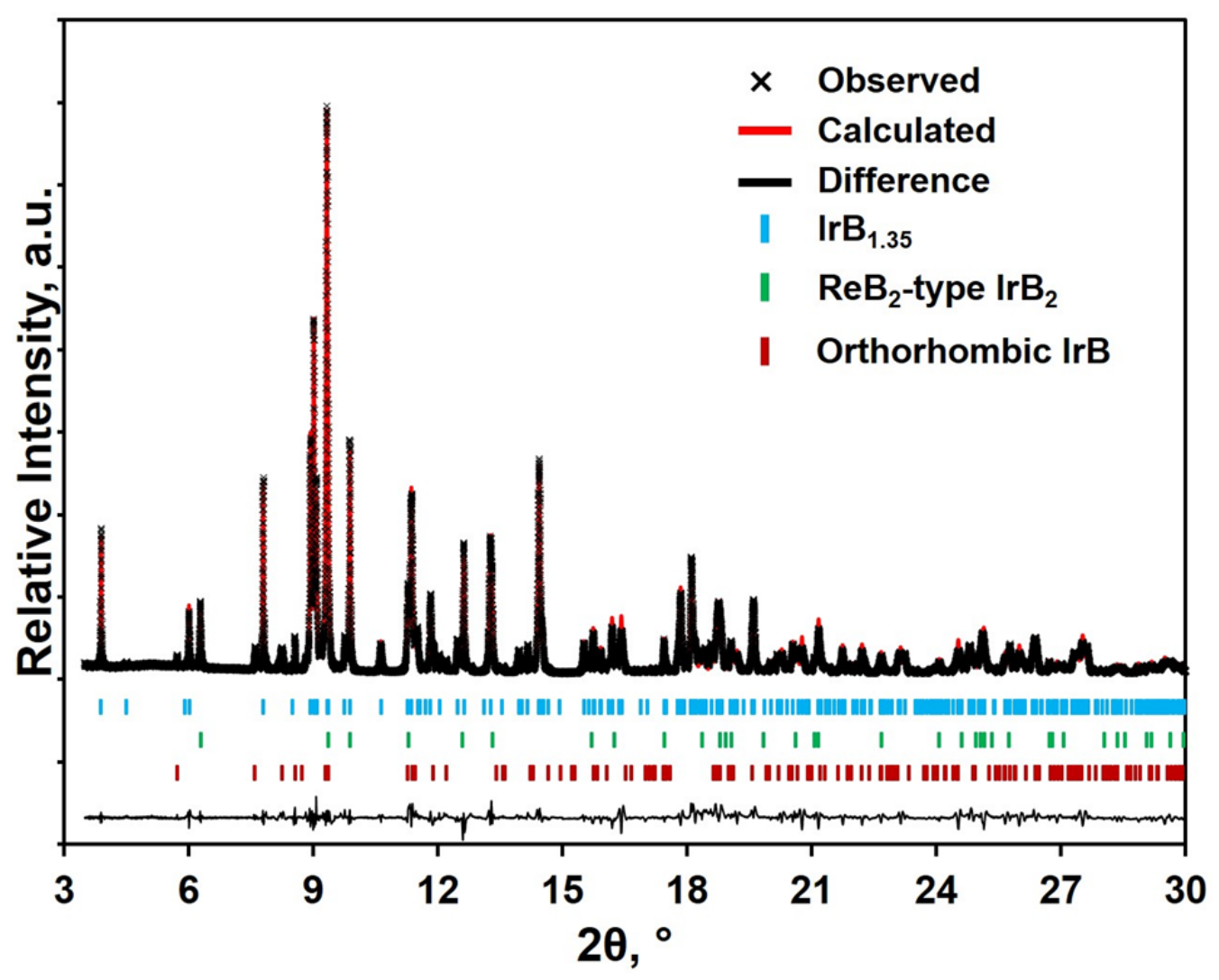

